Article

\title{
Regeneration of Industrial Facilities into Cultural Facilities in Seoul: Studying Location Value
}

\author{
Jun Sik EOM ${ }^{1}$ and Dai Whan AN ${ }^{2, *(1)}$ \\ 1 Department of Urban Planning and Engineering, Yonsei University, Seoul 03722, Korea; \\ archistory67@gmail.com \\ 2 Department of Architecture, Chungbuk National University, Cheongju 28644, Korea \\ * Correspondence: an4229@cbnu.ac.kr; Tel.: +82-10-2757-4229
}

Received: 18 October 2018; Accepted: 11 December 2018; Published: 14 December 2018

check for updates

\begin{abstract}
Seoul is a rapidly developing city that attempted to keep up with the swift rate of industrialization by constructing large buildings with short life cycles to provide basic urban facilities. Today, however, these buildings are obsolete, and Seoul has become a cultural city rather than an industrial one. Rather than destroying these old buildings, many seek to transform them into cultural facilities, thereby giving them location value. This study examines both international and domestic case studies to determine five ways that such revitalization endows these spaces with location value. Through this, the study demonstrates that providing historic buildings with traditional Seoul architectural and urban characteristics with location value creates a meaningful city in which traces of past industrialization coexist with the present. As Seoul continues to develop as a cultural hub in South Korea, this paper's findings suggest directions for future urban design.
\end{abstract}

Keywords: industrialization; Seoul; culture; urban regeneration; location value

\section{Introduction.}

In the West, the Industrial Revolution in the 18th century marked the beginning of rapid urban expansion and population growth. During this time, large buildings were constructed as basic facilities for the effective operation of urban industrialization. However, as more and more industrial facilities no longer served a purpose (ex: Gare d'Orsay, Gasometer Oberhausen in Germany, etc.) due to changes in raw materials and changes in urban structures since the 20th century, issues regarding new uses for existing facilities have started coming to the surface [1,2]. When these buildings lost their main function as a transportation facility or raw material facility, they started serving as cultural facilities through the result of countless agreements from the 1970s to early 1990s. This was an effort to change the city from an industrialization paradigm to a cultural paradigm, and the Western world experienced this change more quickly than in Korea, where this trend only started gaining momentum starting from the 21st century [3].

Unlike in the West, Korea's period of rapid industrialization began in the 1950s. During this time, a quarter of the Korean population moved to cities in a short period of time, and Seoul was forced to hastily construct buildings to house them. Because these buildings were constructed so quickly, they were often large but with short life cycles.

However, today, as in Western cities, the paradigm of industrialization has shifted to one of enculturation. Seoul is now demolishing these old buildings that have completed their industrial purpose. Nonetheless, industrialization remains an important part of Seoul's identity, and thus many methods of dealing with these old buildings—such as demolishing them to construct more profitable structures (i.e., apartments) are un suitable. In addition, because of Seoul's varied geography, the location value of each industrial-era building must be considered separately when planning large urban regeneration [4]. 
Seoul's urban structure is changing rapidly and a solution for how best to treat these buildings is pressing. We believe, therefore, that overseas case studies are the best way to quickly determine a feasible plan for these buildings. Even though Seoul's unique characteristics mean that these case studies must be adapted before being applied, they are the most effective way forward. Despite this, we believe that these case studies can provide us with the tools to determine the location values for industrial-era structure and with resources to create a model for distinguishing the best use of each property based on its unique features.

Therefore, this study assesses individual case studies to determine the respective value of each individual method within the context of Seoul. This study generally recognizes location value but categorized the concept into 5 different types through emotional and subjective reasoning to adopt a qualitative research method that clarifies and strengthens the meaning. The concept and scope of location value is unclear, but this study will discuss it within the aforementioned limited scope and discuss points that differ from the economic aspect, technical aspect, and quantitative aspect. As a result, 5 main planning strategies will be deduced through previous verified overseas case studies from overseas, and the meaning of location value will be strengthened by analyzing the trend of using these strategies in cases in Seoul through the researcher's logical perspective.

The 'location value' mentioned above is a core concept of this study. It is also an original concept in our study. Although this concept is actually invisible and unquantifiable, it is an important factor that can raise the affirmative meaning of what exists as a desire for socio-cultural fulfillment in our perception.

We evaluate the following methods: "remembering a location's history", "a location's complex connections", "invitations to a concealed location", "adding symbolism to a location", and "integrating a walking network into its surroundings". We then applied these methods to relevant examples of industrial-era revitalization projects after 2000 in Seoul to determine location values. In such a way, we hope to provide a means of driving Seoul urban design toward reflecting its identity as a cultural hub in which remnants of past industrialization are visible and continue to hold value.

\section{Background}

\subsection{Construction Paradigms}

The Industrial Revolution emphasized the functionality and economic efficiency of buildings in metropolitan areas. During the early Modernist era, construction was guided by function rather than aesthetic value: Toward an Architecture (1923) of Le Corbusier noted, "A house is a machine for living in" [5]. Moreover, to quickly resolve the residential issue of people growing more populated in cities, a more functional and technical residential format was required, hence there was a strong preference for methods toward an industrialized city. Rather than considering regional features or exhibiting each city's unique and cultural aspects, urban areas were rebuilt on a large scale using standardized guides and average-quality material [6].

Over time, disputes arose regarding the "impersonality of buildings", which resulted in new urban architectural directions and the birth of a new paradigm, "Postmodernism". This marked the end of development-oriented industrialization in metropolitan cities and a shift toward the emphasis of a city's unique culture.

The move toward emphasizing culture reflected many societal changes of the time. First, industrial growth had entered a period of stagnation or decline, and the relationship between rapid economic growth and inequality has decreased. Consequently, residents began to place greater importance on cultural background than on economic growth, which led to a greater demand for cultural facilities.

Second, this shift implies that people were no longer engaged in quick and standardized decision-making prioritizing short-term economic growth, but rather preferred to make decisions based on discussions with city residents about their needs and wants, even if this took more time. 
Because of this, decisions on what to do with older industrial-era buildings were made through ample discussions and with input from different perspectives.

Finally, this shift suggests that urban residents now place more value on pursuing diversity than on the standardized tools of industrialization. This cultural diversity is now expressed through different architectural concepts and in consideration with a building's unique location and setting [7].

\subsection{Location Valune}

City residents have an increasing desire for culture, along with a need to reflect on the past. These two factors work together to increase a city's diversity and to give specific buildings different location value.

First, urban residents seek to grow their cultural networks by expanding the concept of cultural communities beyond a single region or city and by sharing cultural experiences with other people. This expanded cultural network is often the driving force behind revitalizing the economies of post-industrial, economically depressed cities and regions. This kind of economic growth based on cultural enjoyment and tourism differs from that of the past industrial era. It emphasizes the rational part and extroverted, thus providing a judicial impetus for an event.

Second, urban residents have a nostalgia driven by the need to remember and validate both good and bad aspects of the prior industrial era while moving toward a new cultural paradigm. Remembering the past, therefore, is not simply an attempt to reminisce, but to create an emotional bond of sympathy that breaks from the linear trend of industrialization and serves as a justification for remembering the past based on cultural diversity. This emphasizes the emotional and intrinsic aspect of urban revitalization, providing a psychological motive for an event.

According to these two impulses, location value can be defined as the point of contact between the two desires: the emotional urge to remember the past and the desire to expand one's cultural network. It is this balance that drives the attempt to transform industrial-era buildings and revive them into cultural facilities without erasing the memory of their prior functions. In other words, location value expresses the emotional and/or rational will to preserve a given site.

To this end, there have been attempts to revive and use buildings that maintain the paradigm of industrialization but can no longer serve their original purpose. Successful cases of this can be seen around the world as other cities seek to find a path of coexistence between nostalgia and culture in today's urban paradigm shift. Each of these precedents has implications for developing similar projects in Seoul.

\subsection{Five Methods for Determining Location Value}

This study emphasizes approaches to urban revitalization that emphasize the above-mentioned components of location value: the urge to remember the past and the desire to expand one's cultural network.

In more detail, the type of regeneration that pertains to these two factors will be categorized more in depth and the characteristics of each type will be examined. This categorization is based on architectural urban reactions regarding means for satisfying the "urge to remember the past" or the "desire to enjoy culture", which are psychological human desires that may be referred to as subjective as mentioned in the introduction. In other words, this can only be quantitative categorization regarding desires and architectural urban factors, rather than categorization from an economic, technical, or quantitative aspect. Ultimately, the conceptual method of resolving the issue of satisfying the desires of urbanites will be clarified by categorizing different types from the perspective of location value through this categorization. Since these 5 types are concepts that were derived through the two main perspectives of desire that were mentioned above, upon examining each of these further, the "urge to remember the past" can be seen as a strategy that focuses on the given location itself, while "expanding one's cultural network" is a strategy that tries to have an impact on the surrounding location, which can be further explained as follows. 
We further divided the former into the following categories: "remembering a location's history" and "invitations to a concealed location", "Remembering a location's history" is the most basic revitalization strategy. It involves leaving traces of a site's history to show the flow of time and its previous incarnations. By maintaining a location's part functions or appearances, either in part or in full, urban planners and architects can induce a psychological response. Strategies that focus on "invitations to a concealed location" reflect the fact that sometimes industrial sites are meant to prevent visitors, while revitalized facilities must invite them. For example, often facilities in the city center must be moved to the outskirts of town due to urban development. Both these approaches focus on a location or facility's previous identity, creating new features by applying traces of the past even while adapting a facility to its current function (i.e., from industrial to cultural).

We also divided the latter aspect of location value into three categories: "adding symbolism to a location", "a location's complex connections" and "integrating a walking network with its surroundings", "Adding symbolism to a location" can be understood as building a symbolic new facility on an existing site. This is a common approach when revitalizing stagnant or depressed cities. "A location's complex connections" refers to using existing facilities, (i.e., within the city center,) to enable a site's three-dimensional use. This can create environmentally friendly spaces, which are often lacking in the city center, and improve disconnection between areas. Finally, "integrating a walking network with its surroundings" provides a city with continuity by connecting meaningful places or facilities and focusing on predominantly pedestrian spaces instead of vehicular spaces. In each of these three categories, while the site itself is important, the approach focuses more on the surroundings to increase a city's vitality. This can be understood as a more outward-looking way of focusing on a site's relationships with its surroundings and strengthening organic connectivity.

\section{Urban Development in Seoul}

Korea was under Japanese colonial rule from1910-1945, and the country was decimated by the Korean War (1950-1953). It was only after this period, in the mid-1950s, that Korea entered a period of industrialization, thanks to the introduction of the New Community Movement (Saemaeulundong) and multiple five-year economic development plans.

Seoul found itself particularly pressured during this period of rapid industrialization due to the need to restore demolished facilities and provide for explosive population growth. Unable to avoid the risk of war-until 1980s the Korean War was put on hold due to an armistice rather than officially ended-Korea were in the unique position of being able to use the armistice both politically and socially (i.e., military dictatorship and irrational regulations).

Korea's metropolitan cities—represented by Seoul—had no choice but to adopt early Modernist construction methods, which metropolitan cities in the West had used since the 1950s to foster industrialization. To keep up with the fast pace of industrialization, Seoul simultaneously created multiple large-scale buildings and infrastructures, both with short life spans. Situated mere kilometers away from an enemy nation, Seoul was suddenly home to a quarter of the Korean population. Its situation was unique: it grew into an industrialized city with buildings constructed for economic growth while simultaneously preparing for war [8].

In the late 1990s, Seoul's priorities shifted from focusing on industrialization to culture. This shift can be traced back to the 1986 Seoul Asian Games and 1988 Seoul Olympic Games, which portrayed Seoul as an international city. Seoul built new structures and repaired urban facilities in preparation for these events, thereby maximizing its value as an industrial city, while also securing its value as a cultural city by building cultural facilities. After the games were over, an emphasis on the cultural paradigm remained and the city's residents had changed perceptions of their city. This changing view was cemented through numerous other international events, such as the 2002 FIFA World Cup in Korea and Japan.

At the same time, Seoul was rapidly growing into a mega-city of over 10 million people and its infrastructure could not keep up. Large industrial facilities were becoming decrepit while the 
city's spatial growth only considered growing demands for a cultural identity. The result was a growing effort to increase buildings' intrinsic value by imparting meaning on their locations to further architectural planning and contribute to the city's cultural imaginative power. This can be seen in new buildings such as the National Museum of Korean Contemporary History, the Seoul Museum of History, the War Memorial of Korea, and the Seodaemun Prison History Hall, as well as in the restoration of Seoul's palaces.

These projects proceeded independently, but large-scale architectural events were used to unify architect and planners' approach and understanding when engaging in such work. These included the UIA 2017 Seoul World Architects Congress and the 2017 Seoul Biennale of Architecture and Urbanism. The latter, under the slogan "Imminent Commons", held exhibitions and lectures across Seoul, including at the Oil Tank Culture Park (Mapo Cultural Depot), Donuimun Museum Village, Sewoon Plaza, and Dongdaemun Design Plaza. These events also highlighted various projects to combine urban regeneration with existing industrial-era buildings. Hosting events at the Oil Tank Culture Park and Sewoon Plaza, both examples of this type of revitalization, created a platform for various discussions about how best to accomplish this [9].

As a cultural city, Seoul must emphasize its urban landscape and design. The city must develop a way to address the revitalization and continuation of large-scale industrial-era facilities that have completed their life spans. Such a process must continually be integrating new discourse and to add meaning to sites' locations. A necessary-and inevitable-part of this is to compare, review, and verify other examples of such revitalization, both in Korea and abroad, and to assess their value and application in Seoul.

\section{International Case Studies}

This section outlines basic concepts of location value based on the five categories described above through the lens of international case studies. We selected examples that effectively demonstrate what methodology they use to determine location value. As various architectural methods are used when revitalizing a large industrial facility, each study may provide an example of multiple methodologies. These case studies are intended to better explain the five concepts focused on in this paper and are not intended to be compared one-on-one with projects in Seoul, which are detailed in the following section.

\subsection{Remembering a Location's History: Bercy Village, Paris}

The projects in this category are instances in which multiple facilities on a large plot of land were transformed into tourist landmarks by reviving memories of the past. These cases are attempts to "revive a location based on its history and structural characteristics while finding a reasonable balance between conservation and development" [10]. To achieve this, design must consider visitor experience and participation-placing importance on such activities as playing, walking, and watching. According to studies on the sense of place, satisfaction regarding existing natural/artificial physical factors and experience have a major influence on the successful reproduction of a historical place (Table 1).

Table 1. Remembering a Location's History: Bercy Village.

\begin{tabular}{ll}
\hline Bercy Village & \\
\hline Location & Paris \\
Year of establishment & 1999 (Design competition: 1990) \\
Area & $22,900 \mathrm{~m}^{2}$ \\
Change in function & Wine cellar $\Rightarrow$ Commercial facilities \\
Primary Strategy & Remembering a Location's History \\
\hline
\end{tabular}

Located in the southeast of Paris, Bercy Village (Figure 1) is the work of Valode and Pistre, who were chosen to revitalize this historic district through a 1990 design competition. The architects 
created an energized space by remodeling wine cellars and abandoned land around the railway station used to transport wine in the late 19th century. Today, Bercy Village has 42 commercial facilities scattered across approximately 200 meters. It is a place where families come for events and shopping that reflects Parisian culture and the arts. Today, the area is commonly referred to as the "Playground of Parisians".

Bercy Village encourages the flow of visitors by connecting the old railroad with walkways, making the areas easily accessible. The remodeled cellars are situated horizontally on each side, creating a cozy space that seems disconnected from the outside world while offering visitors diverse sights and entertainment [11]. In such a way, Valode and Pistre reused a portion of existing facilities to create a place of rest after the land's original function had been exhausted, a prime example of active urban regeneration.

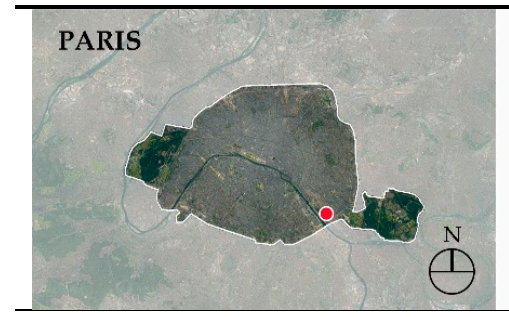

(a)

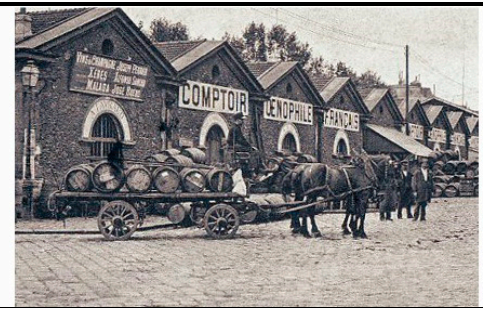

(b)

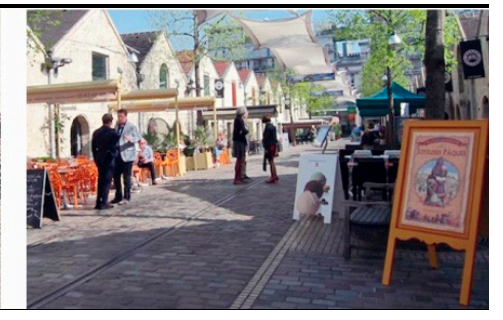

(c)

Figure 1. Bercy Village (a) Site Map; (b) Past; (c) Present. (b) Source: Official Website of Paris Zigzag [12]. (c) Source: Official Website of Retail Square [13].

\subsection{Invitation to a Concealed Location: Tate Modern Gallery, London}

Commercial facilities are typically unwanted structures that tend to be constructed on city out skirts. If they are built within the city, they are typically located in regions that are difficult to recognize or easy to conceal. These unwanted public facilities often take up a relatively large amount of land and space; by turning them into cultural spaces, they become warm, easily approachable spaces instead of cold, concealed spaces rumbling with the mechanical sounds of the past (Table 2).

Table 2. Invitation to a Concealed Location, Tate Modern Gallery.

\begin{tabular}{ll}
\hline Tate Modern Gallery & \\
\hline Location & London \\
Year of establishment & 2000 (Design competition: 1994) \\
Area & $34,500 \mathrm{~m}^{2}$ \\
Change in function & Thermoelectric power plant $\Rightarrow$ Cultural facility \\
Primary Strategy & Invitation to a Concealed Location \\
\hline
\end{tabular}

One prime example of such facilities are thermoelectric power plants, which are generally perceived as an unwanted public facility, despite their necessity. The Tate Modern Gallery (Figure 2) in London is an exemplary case of how such a building can be revitalized, leading to the development of the surrounding infrastructure as well. In 1994, Herzog and De Meuron won an international design competition and turned the Bankside thermoelectric power plant—which has not functioned for 20 years-into a modern art museum.

Built with large gray bricks with a stack height of $99 \mathrm{~m}$ and a length exceeding $200 \mathrm{~m}$, the building's original roof was removed and replaced with U-Glass to allow natural light to enter. On the inside, a lucid exhibition space in a minimalist style creates a gentle ambiance for visitors. Changes to the exterior were minimal - the building took on completely new functions as a cultural space while continuing to embody its historical identity. The addition of a walkway, bridge, and other nearby urban facilities, meanwhile, strengthened the area's connectivity [14]. 


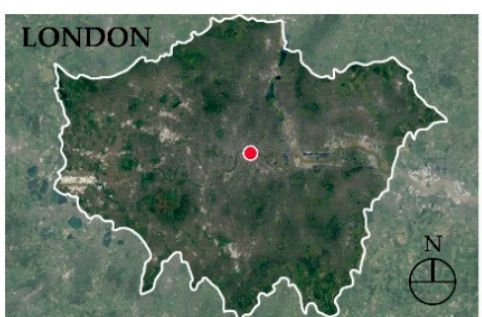

(a)

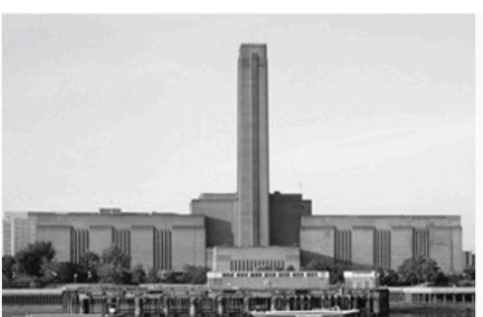

(b)

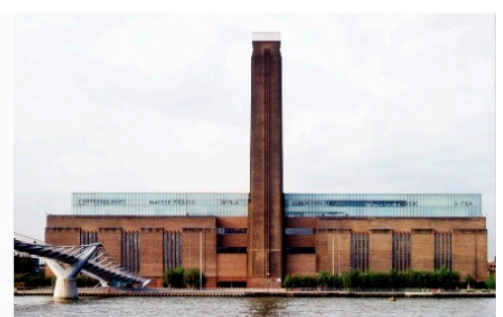

(c)

Figure 2. Tate Modern Gallery (a) Site Map; (b) Past; (c) Present. (b) Source: Official Website of RIBA(Royal Institute of British Architects) (Bankside Power Station) [15]. (c) Source: Official Website of Tourist Destinations [16].

\subsection{Adding Symbolism to a Location: The Guggenheim Museum, Bilbao, Spain}

Adding symbolism to a location is a way to revive regions in decline by constructing new, symbolic buildings rather than simply using old buildings. Such methods can present powerful and symbolic models that have a positive influence on the surrounding area and gradually increase its users. However, for such a symbolic landmark to take shape, the architect must assess the overall problems of the region, have an extremely novel idea for improvement, and establish an appropriate line of communication with local residents. The community itself needs to determine the change in direction-there must be a degree of cultural consensus amid diversity. Having the ability to develop new values and make decisions that incorporate creative designs and diversity are the best means by which to add symbolism to a location [17] (Table 3).

Table 3. Adding Symbolism to a Location: Guggenheim Museum.

\begin{tabular}{ll}
\hline Guggenheim Museum & \\
\hline Location & Bilbao, Spain \\
Year of establishment & 1997 (Design competition: 1992) \\
Area & $24,290 \mathrm{~m}^{2}$ \\
Change in function & Cultural facility (new construction) \\
Primary Strategy & Adding Symbolism to a Location \\
\hline
\end{tabular}

The Guggenheim Museum (Figure 3) in Bilbao, Spain, is the work of Frank Gehry, winner of a 1992 international design competition. At the time, the city was in a recession following the collapse of the iron ore industry, and the competition was intended to raise its economic and social status. Today, the Guggenheim is recognized around the world. This de-constructivist building made the region a focal point of European culture and led to the coining of the term "the Bilbao Effect". As a result of the new building, the surrounding region experienced major development. Indeed, it only took three years to repay the investment funds through tourism income.

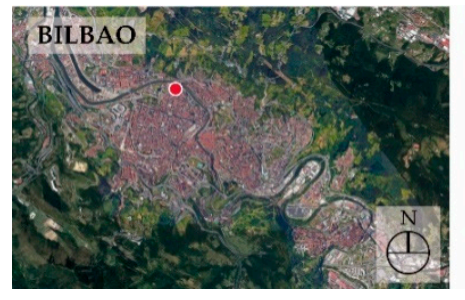

(a)

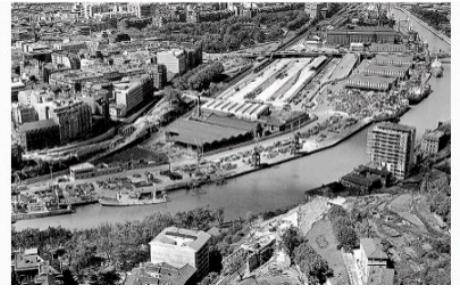

(b)

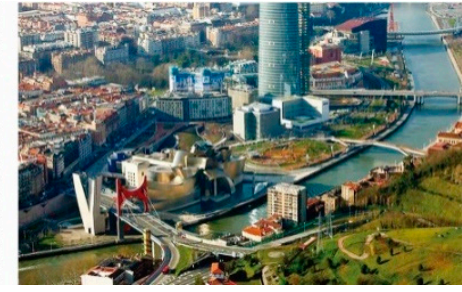

(c)

Figure 3. Location of the Guggenheim Museum (a) Site Map; (b) before Construction; (c) after Construction. (b,c) Source: Blogspot of La Vida Es Como Una Caja De Bombones (Article, 23 March 2011) [19]. 
The Guggenheim Museum looks unconventional from the outside: the structure and exterior recall the sculptural forms of Umberto Boccioni. The building, however, is also connected to the surrounding urban context: today its dynamic form has become the symbol of Bilbao, representing a project that successfully turned a declining city into a global tourist destination [18].

\subsection{A Location's Complex Connections: Olympic Sculpture Park, Seattle}

Railroads and overpasses are linear structures that served a single function: to quickly mobilize traffic networks for effective industrialization. These facilities not only caused physical disconnections between different areas but could also make it difficult for urban residents to establish cultural connections. Indeed, areas surrounding these structures often became slums.

In this section, we examine how planners and architects have used these structures to create leisure spaces and connect regions. By developing them into cultural facilities, these previous divisive structures are transformed into spaces that foster complex regional, social, and cultural connections [20] (Table 4). While we use the Olympic Sculpture Park (Figure 4) in Seattle as our case study in this section, New York's High Line, describe in the next section, is another example of such a project.

Table 4. A Location's Complex Connections: Olympic Sculpture Park.

\begin{tabular}{ll}
\hline Olympic Sculpture Park & \\
\hline Location & Seattle \\
Year of establishment & 2007 (Design competition: 2001) \\
Area & $36,000 \mathrm{~m}^{2}$ \\
Change in function & Open space above a railway $\Rightarrow$ Park \\
Primary Strategy & A Location's Complex Connections \\
\hline
\end{tabular}

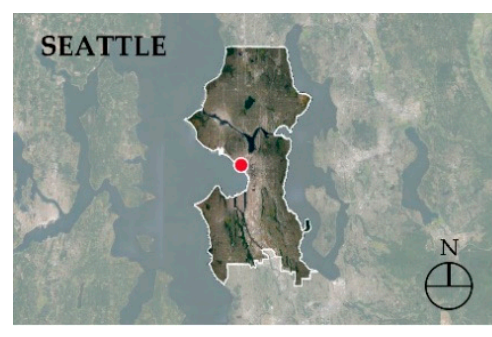

(a)

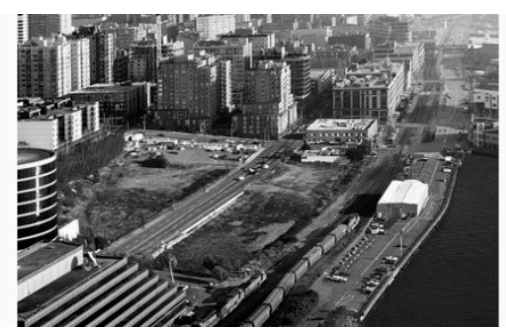

(b)

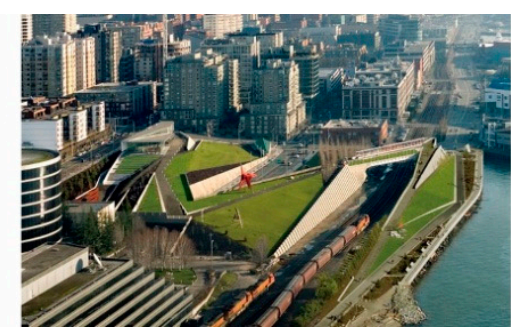

(c)

Figure 4. Olympic Sculpture Park (a) Site Map; (b) Past; (c) Present. (b,c) Source: Official Website of Azure (Article, 24 October 2013) [22].

The Olympic Sculpture Park in Seattle uses artificial slopes, creating a green space and sculpture park to connect the coast with residential districts, which were previously separated by an old railway. This park is the work of Weiss and Manfredi, who were selected in an international design competition in 2001. This project encourages the natural movement of pedestrians and is a representative case of how to use the upper portion of railways for urban redevelopment. (A similar case is the development of Rive Gauche in Paris.)

According to the head architects of this project: The land could be divided up into three major plots. There was the main crossroad and railway that entered the heart of the city from the south, the existing entrance, and wharf. Since there were various means of transportation moving simultaneously, the sense of the land was dynamic, hence the project automatically took on a dynamic personality. We took the approach of a topographical concept that can connect all three categories of land by artificially manipulating the topography [21].

Ultimately, this project separated the flow of the transportation network from that of pedestrians to optimize the walking environment. This allowed for an exhibition route for art and eventually became a landmark in the community. 


\subsection{Integrating a Walking Network with Its Surroundings: High Line, New York}

Creating a pedestrian-centered network is more detailed than the other concepts described in this section. It involves an emphasis on the active connectivity of surrounding regions by incorporating the actual behaviors of residents. Contemporary users desire a space where they can walk comfortably in the city while increasing connectivity between meaningful places. It is thus extremely important to establish a method that connects existing facilities by using walkways and public spaces based on rundown industrial facilities and existent infrastructures. In such a way, cities can improve pedestrian flow disconnected by industrialization and integrate a walking network with nearby buildings. Unlike the other projects described in this section, this requires multiple steps over a long period of time (Table 5).

Table 5. Integrating a Walking Network with its Surroundings: High Line.

\begin{tabular}{ll}
\hline High Line & \\
\hline Location & New York City \\
Year of establishment & 2009 (Design competition: 2004) \\
Length & $2.3 \mathrm{~km}$ \\
Change in function & Old upper portion of railway $\Rightarrow$ Park \\
Primary Strategy & Integrating a walking network with its surroundings \\
\hline
\end{tabular}

The most successful case of an urban pedestrian network is the High Line (Figure 5) project in New York City, which turned an old railway into a park and botanical garden. This was the work of James Corner Field Operations (JFCO), who were selected through an international design competition in 2004 and modeled on the 1990s "Promenade Plantée" built in near the Bastille in Paris.

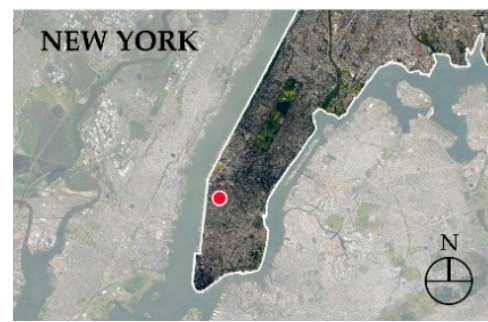

(a)

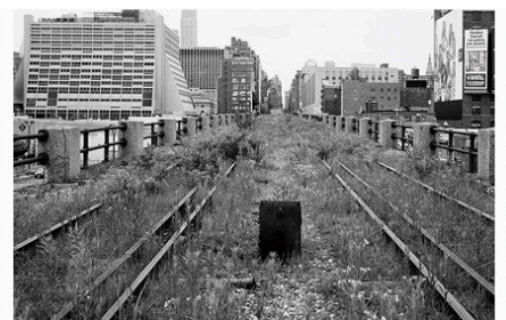

(b)

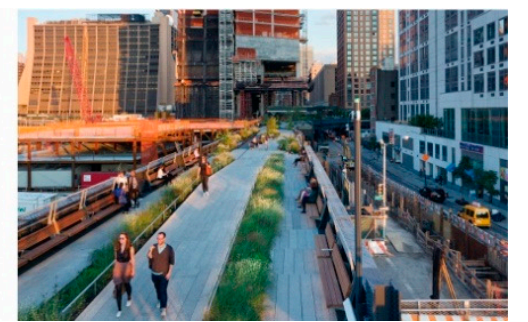

(c)

Figure 5. High Line (a) Site Map; (b) Past; (c) Present. (b) Source: Official Website of Highline Partners (Main page) [24]. (c) Source: Official Website of Curbed__New York (Article, 8 August 2016) [25].

The High Line opened in 2009 (total length: $2.3 \mathrm{~km}$, total area: 28,651 m², height: 0-8.8 m, width: 9-27 m). It is famous for its citizen-oriented facilities, including an observatory, rest areas, exhibition facilities, and botanical gardens, and use of the existing railway structure. As the flow of pedestrians became naturally connected to the existing railway and nearby buildings, it also offered opportunities for distinct improvements in urban development [23].

\section{Location Value in Seoul}

In this section, we examine representative industrial revitalization projects built or scheduled after 2000 and examine them through the lens of the five concepts described above. This provides not only an exemplary precedent for better understanding future revitalization projects in Seoul but is also an opportunity for Seoul to enhance its identity as a cultural city.

\subsection{Seonyudo Park}

An island on the Han River at the center of Seoul, Seonyudo originally served as a purification plant constructed when the city had a much smaller population. As Seoul grew, the plant was 
transferred to a different location. Today, the area is a park created by architect Sung-Yong Joh, who was selected through a design competition in 2000.

Praised by experts, Seonyudo Park (Figure 6) uses the existing purification plant facilities to create an ecological park. The area includes exhibitions, botanical gardens, and other programs open to residents, including theater shows presenting the history of the area. It is famous for breaking down boundaries between the industrial and the cultured, the artificial and natural, the past and present. Each facility is arranged separately, and the visual spaces include walkways, gardens, and other nature programs. This enables the park to serve as a place of leisure and rest for residents in the heart of the city.

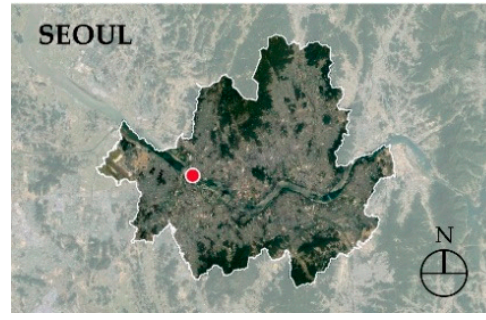

(a)

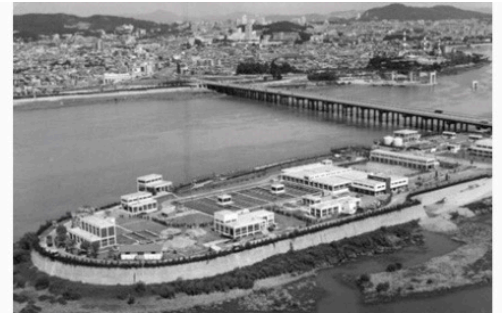

(b)

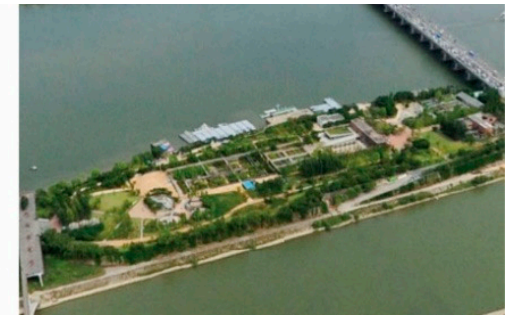

(c)

Figure 6. Seonyudo Park (a) Site Map; (b) Past; (c) Present. (b) Source: Search Google image "Seonyu Jungsujang (선유정수장)" [26]. (c) Source: Capture aerial view from Naver Map (official Website) [27].

This project is a good example of "remembering a location's history" through renovating an existing facility and of "invitation to a concealed location" through its transition from an industrial facility closed to the public to a cultural one that seeks to attract people. Both these methods are examples of a tendency to remember the past, attempts to draw in the public by actively reusing existing facilities to maximize on a location's identity (Table 6).

Table 6. Main Trend of Seonyudo Park.

\begin{tabular}{ll}
\hline Seonyudo Park & \\
\hline Location & Seoul \\
Year of establishment & 2002 (Design competition: 2000) \\
Area & $110,407 \mathrm{~m}^{2}$ \\
Change in function & Purification plant $\Rightarrow$ Park \\
\hline
\end{tabular}

Main Trend: Remembering a location's history/Invitation to a concealed location.

\subsection{Oil Tank Culture Park}

After the global oil crisis of 1972, Seoul established the area that is now the Oil Tank Culture Park (Figure 7) as a large warehouse in which to store oil that could be used by city residents during emergencies, such as the outbreak of a war. It was a Class 1 secure facility and access was restricted. Next to it was a landfill. Situated on the outskirts of Seoul, at the time of its construction it was regarded as a location to be concealed.

However, as the city expanded, this region became part of the city center. The nearby landfill was turned into the World Cup Park, and the 2002 Seoul World Cup Stadium was planned for the area. As such, there was a shift in how this place was conceptualized: it was now a space to which all residents were invited, and the oil storehouse was to be demolished.

The Oil Tank Culture Park in Seoul is the work of RoA(Rhizome of Architects) architects Seo-goo Heo and Jae-sam Lee, whose submission- "Petro: Reading the Story of the Site"-was selected as the winner of a 2014 international design competition. They changed the plans for the area: instead of destroying the oil storehouse, they turned it into a cultural facility and historical exhibit. 
Opened in 2017, this new cultural space incorporated sustainable development due to the potential for eco-friendly and digital media development.

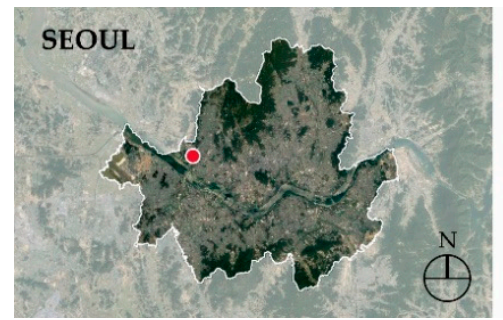

(a)

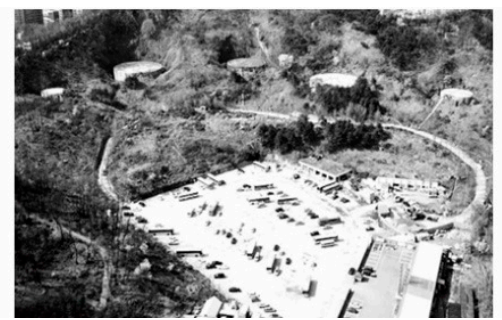

(b)

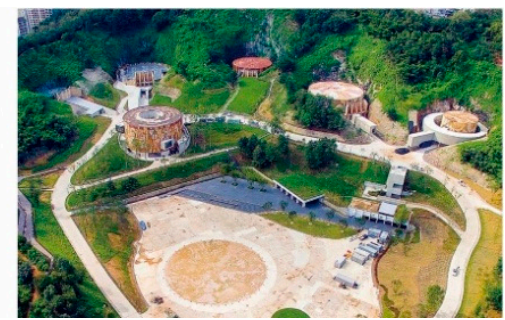

(c)

Figure 7. Oil Tank Culture Park (a) Site Map; (b) Past; (c) Present. (b) Source: Official Website of Ohmynews (Article, 25 August 2017) [29]. (c) Source: Official Website of Seoul Metropolitan Government [30].

The cylindrical form of the existing five oil reserve tanks (height $=15 \mathrm{~m}$, currently 15-38 $\mathrm{m}$ ), the size of 22 soccer fields, remain. Four of the five tanks were turned into theaters and exhibition halls for residents, and a new tank was created by reusing the interior and exterior of existing facilities. The area is now linked to nearby stadiums, parks, and media cities and serves as a new central axis for urban culture and leisure in Seoul [28].

As in Seonyudo Park, this project strongly demonstrates "remembering a location's history" and "invitation to a previously concealed location". Comparing the geographical location of both sites-Seonyudo Park is located on Seoul's Han River and the Oil Tank Culture Park is surrounded by mountains-demonstrates that a place's unique identity is more important in revitalization than its geographical location (Table 7).

Table 7. Main Trend of Oil Tank Culture Park.

\begin{tabular}{ll}
\hline Oil Tank Culture Park & \\
\hline Location & Seoul \\
Year of establishment & 2017 (Design competition: 2014) \\
Area & $140,022 \mathrm{~m}^{2}$ \\
Change in function & Large oil storehouse $\Rightarrow$ Cultural facility \\
\hline
\end{tabular}

Main Trend: Remembering a location's history/Invitation to a previously concealed location.

\subsection{Seongdong Culture and Welfare Center}

Located in Seoul's old city center, the neighborhood of Seongsudong remains packed with small factories and old houses. The Seongdong Culture and Welfare Center (Figure 8), designed by architect Jang-Yoon Gyoo after a design competition in 2008, is the only unique building in the region. It is intended to improve the declining area around it by improving its stereotype as a place in which factories and low-income houses proliferate. Over time, the region's identity has both been preserved and slowly developed as a result.

This building streamlines the pathway and plaza surrounding it, integrating them while also interpreting them three dimensionally. Moreover, while the upper portion of the building has a stereotypical form, the lower portion is intentionally on a slope to emulate the waves of the Han River. The architect, who wished to energize the landscape of a declining city and break free from the image of a closed and impersonal public office [31].

This project is more complicated than the others described above and demonstrates both the desire for an expanded cultural network and to remember the past. For example, it attempts to "add symbolism to a location" and positively impact a stagnant city through new construction. It also shows an "invitation to a previously concealed location", drawing in people to the city center, a previously 
industrial complex. This demonstrates that in urban revitalization, the various methods can be combined and used in different ways (Table 8).

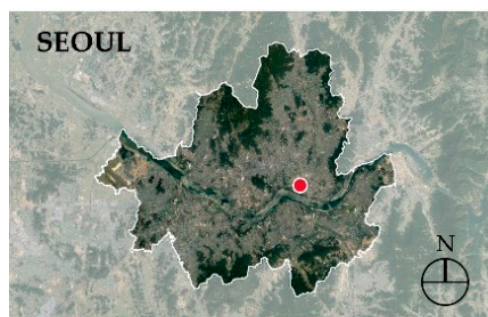

(a)

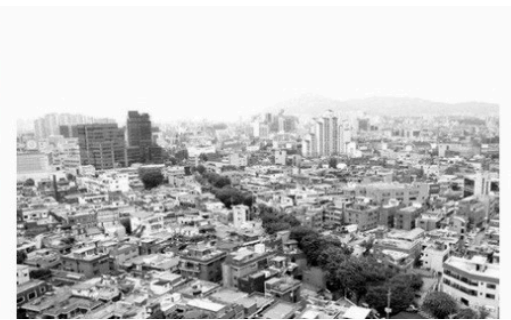

(b)

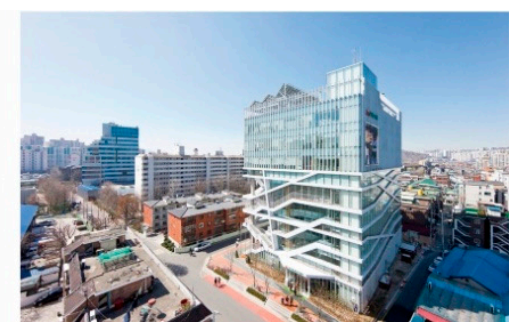

(c)

Figure 8. Seongdong Culture and Welfare Area (a) Site Map; (b) Past; (c) Present. (b) Source: Official Website of Art1 (Article, 22 March 2015) [32]. (c) Source: Official Website of Unsangdong [33].

Table 8. Main Trend of Seongdong Culture and Welfare Center.

\begin{tabular}{ll}
\hline \multicolumn{2}{l}{ Seongdong Culture and Welfare Center } \\
\hline Location & Seoul \\
Year of establishment & 2012 (Design competition: 2008) \\
Area & $9564 \mathrm{~m}^{2}$ \\
Change in function & Cultural facility (new construction) \\
\hline
\end{tabular}

Main Trend: Add symbolism to a location/Invitation to a previously concealed location.

\subsection{Seoullo 7017}

Seoul Station is one of the busiest railway stations in central Seoul. However, the overpass built above it could only be used by automobiles; this caused parts of Seoul Station to become disconnected and turned the surrounding areas into slums. The goal of Seoullo 7017 (Figure 9) was to reuse the overpass (height $=17 \mathrm{~m}$ ) and turn it into a new walkway.

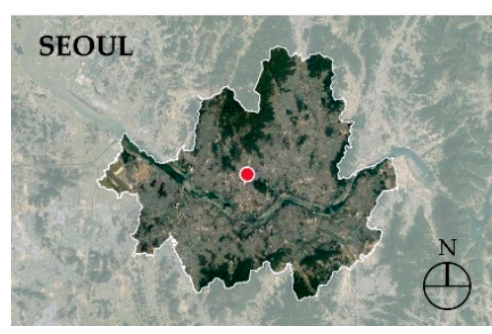

(a)

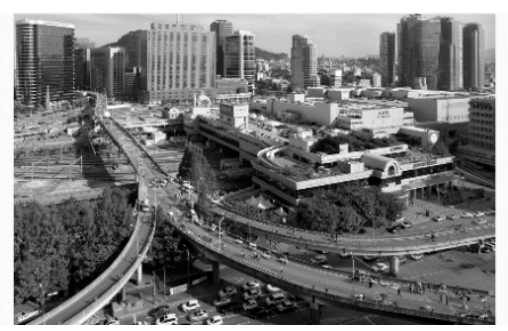

(b)

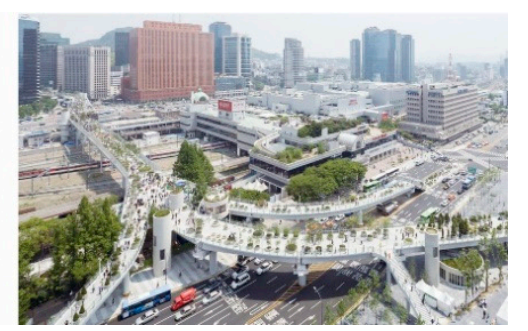

(c)

Figure 9. Seoullo 7017 (a) Site Map; (b) Past; (c) Present. (b) Source: Official Website of Seoul Metropolitan Government [35]. (c) Source: Official Website of Curbed (Article, 24 May 2017) [36].

The MVRDV design office (Winy Maas, Jacob van Rijs, and Nathalie de Vries) one an international design competition for this project in 2015. Their project involved a public elevated walkway (total length $=1.024 \mathrm{~km}$, maximum width $=10.3 \mathrm{~m}$ ), thereby using and connecting previously segregated land. They also developed the space into hanging garden, filling a previously desolate region of the city with complex ecological connections and cultures [34]. In addition to viewing the area's various exhibitions, people could walk without worrying about vehicular disruptions or the complex traffic of railway stations.

Projects such as this one that use existing structures are a method for efficiently using urban areas' limited land. Seoullo 7017-and the Sewoon Plaza project, described in the next section-contribute to reconnecting areas of the city previously fractured by the Seoul railway. 
This project is a prime example of "integrating a walking network with its surroundings", as it links the urban landscape to pedestrian routes. It also demonstrates "a location's complex connections" through its development of the overpass as a dual-purpose structure in a restricted urban area. Finally, it also reflects "remembering a location's history" in that it redeveloped the existing overpass into a public walkway.

This project is often mentioned at the same time as New York's High Line. While both are example of revitalized transportation infrastructures, they differ in that the High Line was built with citizen participation, but this project was led by the Seoul Metropolitan Government. In Seoul, this project was constructed within a short period of time and driven by government revitalization (Table 9).

Table 9. Main Trend of Seoullo 7017.

\begin{tabular}{ll}
\hline Seoullo 7017 & \\
\hline Location & Near Seoul Station \\
Year of establishment & 2017 (Design competition: 2015) \\
Area & $1024 \mathrm{~m}^{2}$ \\
Change in function & Unused space on an overpass $\Rightarrow$ Park \\
\hline
\end{tabular}

Main Trend: Integrating a walking network with its surroundings/A location's complex connections/Remembering a location's history.

\subsection{Dasi-Sewoon Project}

Built in the late 1960s, the Sewoon Plaza was designed by Swoo-Geun Kim, a major architect in Korea. It is a large facility, spanning a kilometer and connecting Namsan and Jongmyo. At one time, it served as a major axis connecting various city infrastructures and was the first multipurpose facility to include an innovative mix of factories, shopping areas, and residential areas.

However, Dasi-Sewoon Plaza (Figure 10) became a slum as it aged, and there were ongoing discussions on whether to demolish this facility. However, in 2015 the "Modern Vernacular" project from E-Scape Architects was selected in an international design competition, and the space was transformed into a public space. Building is still underway, but the core of the project is an elevated walkway that connects major pathways—-such as Euljiro, Cheonggyecheon, and Jongno-along the Namsan axis. It is intended to connect different areas of the city as well as to serve as a cultural and leisure space for citizens. The space provides a place of rest and exhibition, while facilities are being improved by remodeling existing buildings and programs encourage citizen participation. These programs include various visual events in the outside spaces and are centered around the flow of the deck, which is connected to nearby buildings [37,38].

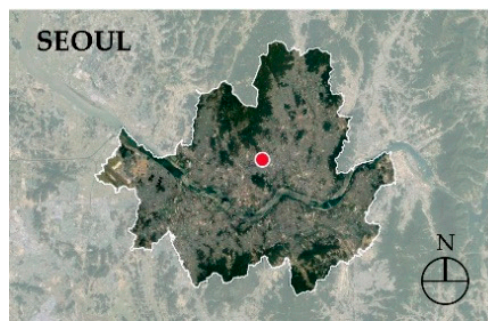

(a)

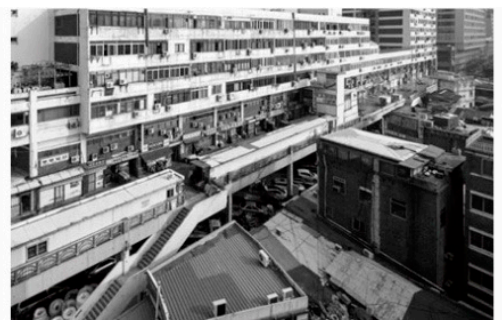

(b)

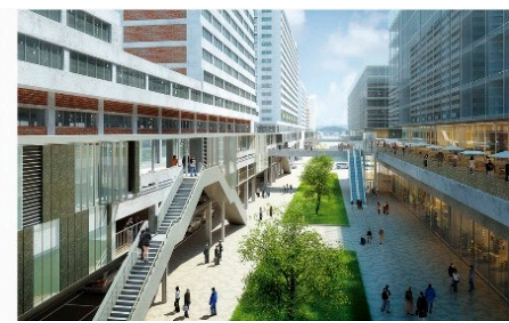

(c)

Figure 10. Dasi-Sewoon Plaza (a) Site Map; (b) Past; (c) Present. (b) Source: Official Website of Korean Broadcasting System (Article, 16 January 2016) [39]. (c) Source: Official Website of Designhouse (Magazine, April 2016) [40].

This project, as with Seoullo 7017, reflects "remembering a location's history", "integrating a walking network with its surroundings", and "a location's complex connections" through its revitalization of existing facilities. However, these projects differ in terms of function: in Seoullo 7017 
the inherent function of the overpass changed completely, becoming a walkway. The Sewoon Plaza, however, while it has been improved, retains its unique function as a public walkway combined with mix-use buildings. Furthermore, Seoullo 7017 is an active complex with an upper walkway and lower vehicle route, while this project is more passive, serving to connect other spaces with upper and lower spaces focused around walkways (Table 10).

Table 10. Main Trend of Dasi-Sewoon Plaza.

\begin{tabular}{ll}
\hline Dasi-Sewoon Plaza & \\
\hline Location & Seoul \\
Year of establishment & 2023 (Scheduled completion) (Design competition: 2015) \\
Area & $205,897 \mathrm{~m}^{2}$ \\
Change in function & Multipurpose facility $\Rightarrow$ Complex cultural hub \\
\hline
\end{tabular}

Main Trend: Integrating a walking network with its surroundings/A location's complex connections/Remembering a location's history.

\section{Assigning Location Values to Buildings in Seoul}

\subsection{Strategy}

Seoul developed into an industrialized city in an extremely short period of time and is a rare example of a city that shifted quickly from a focus on the industrial to one on culture. Consequently, the city has a unique urban structure that demonstrates its strength while meeting the demands of both the industrial and cultural paradigms. In other words, Seoul was forced to address the scores of old industrial facilities quickly coming to the end of their lifespan while also meeting various cultural demands.

There are many tools available to city planners and architects as the city determines how to handle these two demands. First, it is possible to use examples of successful international projects, such as those referenced above, as precedents. These are a useful tool for three different reasons. First, in a time of rapid change, it is difficult for multiple plans to succeed if all are based on the same model. Various precedents can provide different models for urban revitalization, thereby meeting the varied demands of citizens without relying on only a few models that may not meet all of the people's needs. Second, there are few successful examples of urban revitalization in Seoul, or even Korea; there is therefore no choice but to learn from examples in other countries. Third, architects from around the world are now entering plans into international competitions and exhibitions, and there is an increased preference for successful international examples.

Second, it is necessary to develop an accurate understanding of precedents and applied case studies to apply them to future urban design. The five categories used in this study can all be understood through overseas examples and better applied to domestic projects. These case studies also demonstrate how one project may reflect multiple revitalization strategies. For example, both Seonyudo Park and the Oil Tank Cultural Park reflect "remembering a location's history" and "invitation to a previously concealed location" while both Seoullo 7017 and Dasi-Sewoon demonstrate "a location's complex connections", "integrating a walking network with its surroundings" and "remembering a location's history".

Third, understanding how each of these five concepts is used in previous projects allows them to be applied to future urban revitalization. Seoul's unique urban characteristics and social, cultural, and emotional factors make it inherently difficult to uniformly apply the approaches used in overseas examples. Better understanding these international case studies and the individual concepts behind them allows us to clearly assess their characteristics and whether they are applicable to urban revitalization in Seoul. In this way, urban planners may use these methods to secure diversity and find consensus among citizens. 


\subsection{Characteristics of Location Value in Seoul}

The international examples described in this study illustrate five different ways architects and urban planners give a site location value. These examples suggest strategies that may enable Seoul to successful renovate industrial-era buildings, providing them with location value to coexist in the city's contemporary landscape. Such strategies and the resulting diverse methods of urban revitalization are essential, because no standardized plan can meet the growing demand for cultural diversity. As described in Section 2, cities must incorporate citizens' growing stress on culture in any new development.

These five strategies have different implications for revitalizing the urban fabric of Seoul. For example, the drive to remember the city's past - the first general goal of revitalization-is closely related to a location's history. This is especially important for Seoul's large elderly population, whore member the city before industrialization. These people witnessed the industrialization of the city and are now seeing it transform again into a cultural hub. When they and middle-aged generations share these memories with future generations, they actively drive a societal focus on culture. In this way, institutional memory can also lead to increased culture.

The second general purpose of revitalization, expanding a city's cultural network, is just as vital. This is expressed through attempts to develop a regional economy based on a cultural paradigm, transforming buildings into cultural facilities that can increase self-production and spending by attracting people from other regions to visit and increasing tourism revenue.

Other, more specific methods discussed in this paper, such as "remembering a location's history" or "adding symbolism to a location" are classic and universal methods of enabling the location value of one site to spread throughout the entire city. "Invitation to a previously concealed location", meanwhile, is valuable in that they resolve the difficulties involved in transforming unwanted facilities-often the remnants of industrialization once concealed from citizens-into public cultural facilities. Finally, "a location's complex connections" and "integrating a walking network with its surroundings " create cultural and social connections between buildings that were once functionally separated in large, industrialized cities.

\section{Conclusions}

Rather than demolishing industrial-era buildings that no longer serve their original purpose, Seoul is seeking to transform these buildings into cultural facilities that exist harmoniously within the city's landscape. These sites are renovated in such a way that gives them location value, a middle ground that satisfies both residents' historical and cultural priorities.

This study examines two characteristics of location value: the demand for remembering the past and the need to expand a city's cultural network. We further categorized these two concepts into five groups: "remembering a location's history", "invitation to a previously concealed location", "adding symbolism to a location", "a location's complex connections", and "integrating a walking network with its surroundings". We examined how these strategies were used in international examples, and then how they have been incorporated into projects within Seoul. The international case studies examined only the primary strategy in each example, while a more extensive approach was taken in the Seoul examples, where we examined how all the five categories were expressed in different projects.

Furthermore, this case study-oriented study can serve as an index for assessing the direction of design strategies of future regeneration projects for decrepit industrialized cities in addition to analyzing projects that are already built. The two important characteristics and five concepts are creative strategies for creating value and may be useful in the field of construction and urban regeneration. Because this study is based on the emotional and subjective concept of 'location value,' it can be used as basic data for an accurate analysis of the psychological urges of urban residents and analyzing the resulting relationships regarding urban architectural reactions. This study also showed that the psychological urges of urban residents and the resulting architectural reactions inevitably 
become important factors of consideration in plans for regenerating unwanted public facilities in a city. In other words, the strategies of "remembering a location's history" and "invitations to a concealed location", which are "urges to remember the past", allow people to recognize traces of a location's history as a factor of remembrance in their perception, which increases the value of the new function on the land. Moreover, the strategies of "adding symbolism to a location", "a location's complex connections", and "integrating a walking network with its surroundings", which pertain to "expanding one's cultural network", emphasize the organic link between a given location and the surrounding environment, so that serving as the energizer of the city center is the core factor of architectural urban reactions, which means that relevant plans to this end must be considered as a necessity.

As the examples of urban revitalization in Seoul show, a times the emotional demand for remembering the past and the rational demand for expanding cultural networks appear separately, while at times they work together within the same project. The case studies examined in this paper show that often several of the five concepts were used in the same project, both in Seoul and internationally. This analysis reflects on the distinct characteristics of Seoul and can be used as a reference when discussing urban renewal in Seoul or similar regions. While the characteristics described in this study are universal concepts for imparting location value to industrial-era buildings, they have a unique expression in Seoul. Understanding this will help urban planners and architects better establish similar places in the future.

Author Contributions: All of the authors contributed equally to this work. All authors have read and approved the final manuscript.

Funding: This research received no external funding.

Conflicts of Interest: The authors declare no conflict of interest.

\section{References}

1. Official Website of Musée d'Orsay. Available online: https:/ /www.musee-orsay.fr/en/collections/historyof-the-museum/the-station.html (accessed on 15 November 2018).

2. Copic, S.; Dordevic, J. Transformation of Industrial Heritage an Example of Tourism Industry Development in the Ruhr Area (Germany); Issue 2 of Geographica Pannonica; Geographica Pannonica: Novi Sad, Serbia, 2014; Volume 18, pp. 43-50.

3. Sung, J.-S. A Study on the Direction and Strategies for Industrial Facility Renewal. In The Journal of Cultural Policy; Korea Culture \& Tourism Policy Institute: Seoul, Korea, 2005; Volume 17, pp. 105-141.

4. Gelézeau, V. SEOUL: Giant City, Radiant Cities; CNSR: Paris, France, 2003; ISBN 2271060850.

5. Corbusier, L. Toward an Architecture, 3rd ed.; Flammarion: Paris, France, 2005; ISBN 2081217449.

6. Panerai, P.; Castex, J. Urban Forms: The Death and Life of the Urban Block; Rotledge: Abingdon, UK, 2004; ISBN 0750656077.

7. Yim, S.-J. Modern Architecture and New Humanism; Ewha Womans University Press: Seoul, Korea, 2003; ISBN 8973005219.

8. Cho, M.-R. Trend and Prospect of Urbanization in Korea: Reflection on Korean Cities. In The Journal of Economy \& Society; The Association of Korean Researchers on Industrial Society: Seoul, Korea, 2003; Volume 60, pp. 10-39.

9. Official Website of 2017 Seoul Biennale of Architecture and Urbanism. Available online: http:/ / seoulbiennale. org/en/introduction/imminent-commons (accessed on 13 September 2018).

10. Im, S.-B.; Kwon, Y.-K. Internal Structure of the Sense of Place for Parks that were Aimed at Reenacting the Place Memory, Focusing on Seoul Park and Seonyudo Park. J. Korean Inst. Landsc. Archit. 2014, 42, 3. [CrossRef]

11. Kim, S.-H. A Study on Creation of "The Third Place" by Renovating Idle Industrial Facilities in the City. Master's Thesis, Inha University, Incheon, Korea, 2014.

12. Official Website of Paris Zigzag. Available online: https://www.pariszigzag.fr/histoire-insolite-paris/ letonnante-histoire-de-bercy-village (accessed on 7 August 2018). 
13. Official Website of Retail Square. Available online: http://www.retail-square.com/shops/bercy-village (accessed on 7 August 2018).

14. Cho, Y.-J. A Study on Method of the Conversion of Idle Industrial Facilities for Urban Regeneration. Master's Thesis, Hanyang University, Seoul, Korea, 2011.

15. Official Website of RIBA (Royal Institute of British Architects). Available online: https: / / www.architecture.com/image-library /RIBApix/gallery-product/poster/bankside-power-stationnow-tate-modern-southwark-seen-from-st-pauls-walk-city-of-london/posterid/RIBA6045.html (accessed on 15 November 2018).

16. Official Website of Tourist Destinations. Available online: http://www.tourist-destinations.com/2014/07/ tate-modern-museum-london.html (accessed on 7 August 2018).

17. Kim, H.-O.; Lee, S.-J. Issue Briefing; Jeonbuk Development Institute: Jeonju, Korea, 2011; Volume 28.

18. Oh, J.-H. A Study on the Form and Space Formation of Frank Gehry's Architecture. Master's Thesis, University of Seoul, Seoul, Korea, 2007.

19. Blogspot of La Vida Es Como Una Caja De Bombones (Article, 23 March 2011). Available online: http: / / lavidadeoxel.blogspot.kr/2011/03/bilbao-hace-40-anos-y-ahora.html (accessed on 10 August 2018).

20. Cha, J.-Y.; Lim, K.-R. An Institutional Improvement for Multi-Purpose Use of Spaces under the Elevated Roads and Railways; Architecture \& Urban Research Institute: Gyeonggi, Korea, 2012.

21. Suh, Y.-R. Seattle Olympic Sculpture Park and Creative City; SNU Open Repository: Seoul, Korea, 2016.

22. Official Website of Azure (Article, 24 October 2013). Available online: https:/ /www.azuremagazine.com/ article/qa-marion-weiss/ (accessed on 10 August 2018).

23. Park, K.-H.; Kim, J.-C. KRIHS Policy Brief; Korean Research Institute for Human Settlements: Anyang, Korea, 2014; No. 448.

24. Official Website of Highline Partners (Main page). Available online: https://www.highln.com/ (accessed on 13 August 2018).

25. Official Website of Curbed_ New York (Article, 8 August 2016). Available online: https:/ / ny.curbed.com/ 2016/8/8/12401622/high-line-real-estate-development-effect (accessed on 13 August 2018).

26. Search Google image "Seonyu Jungsujang (선유정수장)". Available online: http:/ / ojsfile.ohmynews.com/ STD_IMG_FILE/2011/1004/IE001354317_STD.jpg (accessed on 13 August 2018).

27. Capture Aerial View from Naver Map (official Website). Available online: https://map.naver.com/ (accessed on 17 August 2018).

28. Oil Tank Culture Park in Seoul Homepage. Available online: http://parks.seoul.go.kr/template/sub/ culturetank.do (accessed on 17 August 2018).

29. Official Website of Ohmynews (Article, 25 August 2017). Available online: http:/ / www.ohmynews.com/ NWS_Web/View/at_pg.aspx?CNTN_CD=A0002353964 (accessed on 20 August 2018).

30. Official Website of Seoul Metropolitan Government. Available online: http://love.seoul.go.kr/asp/ articleView.asp?intSeq=4912 (accessed on 20 August 2018).

31. Unsangdong Architects Homepage. Urban Regeneration Accelerator. Available online: http://www. usdspace.com/\#overlay=v/architecture/2013/9 (accessed on 20 August 2018).

32. Official Website of Art1 (Article, 22 March 2015). Available online: http://art1.com/news/index.php?at= read\&subm $=3 \& i d x=94084$ (accessed on 20 August 2018).

33. Official Website of Unsangdong. Available online: http:/ / www.usdspace.com/\#overlay=v/architecture / 2013/9 (accessed on 20 August 2018).

34. Kim, J.-A. Urban Garden as Part of Urban Regeneration Programs. Master's Thesis, Hongik University, Seoul, Korea, 2017.

35. Official Website of Seoul Metropolitan Government. Available online: http://cis.seoul.go.kr/TotalAlimi_ new / HistoryBoardDtl.action?seq=8132 (accessed on 22 August 2018).

36. Official Website of Curbed (Article, 24 May 2017). Available online: https:/ /www.curbed.com/2017/5/24/ 15687078/seoullo-7017-sky-garden-mvrdv (accessed on 22 August 2018).

37. Shim, J.-H.; Sohn, M.-G. Methodology of Sewoon MXD-use Apartment Complex Planning Considering Spatial Configuration. J. Archit. Inst. Korea 2007, 23, 11-18.

38. Kim, M.-K. Spatial Imaginary of Site-specific Art. Master's Thesis, Sogang University, Seoul, Korea, 2017. 
39. Official Website of Korean Broadcasting System (Article, 16 January 2016). Available online: http://mn.kbs. co.kr/mobile/news/view.do?ncd=3216514 (accessed on 22 August 2018).

40. Official Website of Designhouse (Magazine, April 2016). Available online: http:/ / mdesign.designhouse.co. $\mathrm{kr} /$ article/article_view/101/73505 (accessed on 22 August 2018).

(C) 2018 by the authors. Licensee MDPI, Basel, Switzerland. This article is an open access article distributed under the terms and conditions of the Creative Commons Attribution (CC BY) license (http:/ / creativecommons.org/licenses/by/4.0/). 